\title{
EMPREENDEDORISMO COMO COMPONENTE PARA DESENVOLVIMENTO DE RESPONSABILIDADE ECONÔMICA NO ENSINO FUNDAMENTAL
}

\section{ENTREPRENEURSHIP AS A COMPONENT FOR THE DEVELOPMENT OF ECONOMIC RESPONSIBILITY IN FUNDAMENTAL EDUCATION}

\author{
MORRIESEN, Eliane Maria ${ }^{1}$ \\ URBAN, Juliane Retko ${ }^{2}$ \\ CAMPOS, Débora Barni de ${ }^{3}$ \\ MATOS, Eloiza Aparecida Silva Avila de \\ FRASSON, Antônio Carlos ${ }^{5}$
}

\begin{abstract}
RESUMO
O empreendedorismo nas escolas de Ensino Fundamental é um movimento educacional ainda recente no país e relevante, dado as constantes mudanças no cenário sócio, político e econômico da nação. Por meio de pesquisa aplicada com questionários, o estudo aconteceu em uma escola da região Sul que tem no currículo pleno a matéria de empreendedorismo desde $01^{0}$ ano do Ensino Fundamental. Os pesquisadores ensinaram economia doméstica por meio dos itens da cesta básica nacional, tomando como objetivo principal desta pesquisa a formação empreendedora. Os resultados mostraram que as crianças alvo do $4^{\circ}$ e $5^{\circ}$ anos têm boa percepção em relação à quantidade consumida nos lares, referente aos itens do objeto estudado. Porém, ainda necessitam de uma visão mais aproximada da realidade quando se trata do valor consumido mensalmente/residência, legitimando a importância de se estudar empreendedorismo desde tenra idade. Conclui-se que há mais de uma maneira de se ensinar economia doméstica, fazendo perpassar o assunto por disciplinas como matemática, ciências, geografia e história, ao contextualizar os temas globais para as realidades locais do alunado.
\end{abstract}

Palavras-Chave: Empreendedorismo; Educação financeira; Economia doméstica; Ensino fundamental; Sustentabilidade.

\section{ABSTRACT}

Entrepreneurship in elementary schools is an educational movement is still a very recent and relevant phenomenon in Brazil, given the constant changes in the nation's social, political

\footnotetext{
${ }^{1}$ Mestranda do Programa de Pós Graduação em Ensino de Ciência da Universidade Tecnológica Federal do Paraná, UTFPR - campus de Ponta Grossa.

${ }^{2}$ Mestranda do Programa de Pós Graduação em Ensino de Ciência da Universidade Tecnológica Federal do Paraná, UTFPR - campus de Ponta Grossa.

${ }^{3}$ Doutoranda do Programa de Pós Graduação em Ensino de Ciência da Universidade Tecnológica Federal do Paraná, UTFPR - campus de Ponta Grossa. e-mail: debarni@hotmail.com

${ }^{4}$ Professora do Programa de Pós Graduação em Ensino de Ciência e Tecnologia da Universidade Tecnológica Federal do Paraná, UTFPR - campus de Ponta Grossa.

${ }^{5}$ Professor do Programa de Pós Graduação em Ensino de Ciência e Tecnologia da Universidade Tecnológica Federal do Paraná - campus de Ponta Grossa.
} 
and economic scenario. Through research applied by means of questionnaires the study was conducted in a school in the Southern region of the country that has entrepreneurship in its curriculum since the first year of Elementary School. The researchers taught domestic economics using items of the national basic foods list. The research's main objective was entrepreneurial education. The results showed that target children in the 4th and 5th grades have a good perception regarding the quantity of food consumed in the homes. However, they still need a more accurate understanding when it comes to the monthly financial value of the consuption, thus legitimizing the importance of studying entrepreneurship beginning at an early age. One can conclude that there is more than one way of teaching home economics, reaching out to other subjects such as mathematics, sciences, geography and history contextualizing global themes to local realities of the students.

KEYWORDS: Entrepreneurship; Financial education; Home economics; Elementary School; Sustainability.

\section{INTRODUÇÃO}

Diferentemente do que o senso comum propõe, não se define empreendedorismo como simplesmente a abertura ou operação de um negócio, mas sim como uma educação para a cultura e para a atitude empreendedora.

É notória, também, a crescente adesão de lideranças de diferentes esferas quanto a este tema. Lideranças políticas, empresários e executivos vêm reconhecendo a importância do investimento na formação de uma cultura empreendedora. Observa-se a grande carência de mão de obra qualificada nos mais diversos setores econômicos de nosso país.

No entanto, sem uma atitude educativa de longo prazo, não há crescimento econômico que se sustente em todas as esferas da sociedade. Diante disso, com o ensino do empreendedorismo para os alunos do ensino fundamental, o educador será um importante facilitador de uma cultura de conscientização da economia. Assim poderá facultar o desenvolvimento das competências nas crianças, através dos ensinamentos, para que se torne cidadã, desde a tenra idade, auxiliando na construção de uma sociedade economicamente mais equilibrada.

O objetivo deste trabalho primou por ensinar economia doméstica na disciplina de empreendedorismo para crianças dos $4^{\circ}$ e $5^{\circ}$ anos de uma escola particular da região Sul, por meio dos itens da cesta básica nacional brasileira.

\section{EMPREENDEDORISMO: UMA VISÃO MACRO E AS CONEXÕES COM TEORIAS EDUCACIONAIS}

No Brasil, o tema vem ganhando cada vez mais espaço na mídia, sendo facilmente observado em programas de rádio, reportagens televisivas, revistas de grande circulação, matérias de jornais e inúmeros portais da internet. Essas informações são sistematicamente debatidas ao longo dos trabalhos e aprofundadas para uma análise crítica da realidade, visando ao desenvolvimento pessoal e profissional do educando, apoiando-nos em uma educação preventiva, que visa à 
saúde laboral e à qualidade de vida, além de uma prosperidade responsável e sustentada.

Lideranças políticas, empresários e executivos vêm reconhecendo a importância do investimento na formação de uma cultura empreendedora por meio de uma educação também empreendedora. É notória, também, a crescente adesão de lideranças de diferentes esferas quanto a esses temas. Sem uma atitude educativa de longo prazo, não há crescimento econômico que se sustente em todas as esferas da sociedade. Assim, percebe-se facilmente um consenso quanto à percepção de que a cultura do empreendedorismo tem apenas um caminho: a educação iniciada na educação básica e continuada por toda a vida do indivíduo.

A pedagogia de Paulo Freire (FREIRE, 1974), também citada por alguns autores como a pedagogia libertadora, defende um sistema de educação que enfatiza o aprendizado como uma ação de cultura e liberdade sendo um processo interativo entre professor-aluno e aluno-professor, pois ambos aprendem.

Demonstra-se, por meio de diversos estudos, que a identidade de um indivíduo é sempre fruto de construções recíprocas emanadas de seu grupo de pertencimento (CHRISTAKIS, 2009).

$\mathrm{Na}$ atualidade, um de nossos desafios é conjugar as muitas identidades e papéis sem perder a percepção de quem somos (BAUMAN, 2005). É justamente diante de um mundo cada vez mais múltiplo, com novas verdades e desejos, que precisamos educar nossas crianças e adolescentes para que, a partir do seu autoconhecimento e do protagonismo de sua narrativa de vida, não se percam na anomia da contemporaneidade.

É pela problematização que educador-educando e educando-educador fixam o ponto de partida para a conscientização. Cabe ao educador-educando problematizar a visão de mundo dos educandos-educadores que, por uma série de razões, podem não estar aptos a entender a realidade criticamente. A conscientização exige o pensar crítico, capaz de procurar a causalidade profunda dos acontecimentos, fazendo o desvelamento da realidade.

A problematização se faria, assim, através do esforço pelo qual educadores eeducandos iriam percebendo, criticamente, como estão sendo no mundo com que e em que se acham (FREIRE, 1974).

Os pressupostos da Pedagogia Crítica de Antonio Gramsci (GHIRALDELLI, 2000) respaldam a visão da pessoa humana e de sua relação com os ambientes educativos, quando afirmam: que o homem é um ser que se constitui como síntese de múltiplas determinações, como um conjunto de relações sociais. Também afirmam que a educação identifica-se com o processo de hominização e estabelece um ensino que parte de uma relação real entre educador e educando. Explicitam que o processo educativo implica uma ação-reflexão-ação como constituintes inseparáveis da práxis educativa; que nos ambientes educativos deve haver a busca 
pelo diálogo como fonte de aprendizagem, havendo a interação de uns com os outros. E, finalmente, a educação busca a formação integral do educando.

A Pedagogia Progressista (SNYDERS, 1976) vê a educação como um meio para a compreensão da realidade histórico-social e explicita o papel do professor transformador dessa mesma realidade. A ênfase à interação entre professor (mediador), aluno, conhecimento, contexto social e o provimento dos meios necessários para que os educandos não apenas assimilem o saber objeto enquanto resultado, mas aprendam o processo de sua produção, bem como as tendências de sua transformação, são caminhos pelos quais os educadores podem ensinar o empreendedorismo.

Muitos educadores, filósofos e pensadores influenciam o olhar, na medida em que a tônica do trabalho está focada para a formação humana, o desenvolvimento pessoal e profissional do educando, além da elaboração de um projeto de vida ético e sustentável.

\section{O ENSINO DO EMPREENDEDORISMO NA ESCOLA}

De acordo com Flores et al. (2008), a Educação é o passo fundamental para o desenvolvimento de empreendedores, tanto que diversos países já possuem em seus currículos a presença da disciplina 'empreendedorismo'. Como exemplo, a Escócia, Espanha, Finlândia, Luxemburgo, Noruega, Suécia e Portugal.

Dornelas (2008) assevera que, no Brasil, o empreendedorismo já está saindo dos bastidores para ocupar o local de destaque, seguindo exemplos de países desenvolvidos como os Estados Unidos, que formam empreendedores que impulsionam a economia do país.

A respeito do surgimento da disciplina de empreendedorismo, Filion (1999, p. 11) explicita que:

O desenvolvimento do empreendedorismo foi de uma disciplina que não seguiu padrões semelhantes a outras disciplinas, visto que grandes números de pesquisadores cada um usando sua cultura, lógica e metodologia, começaram a se interessar no trabalho de campo de empreendedorismo de pequenos negócios.

Conforme Vieira et al. (2011), para que a educação e consequente formação de futuros empreendedores ocorra alinhada com 0 mercado, 0 ensino de empreendedorismo precisa ser contextualizado, explorando conteúdos além da sala de aula. Os métodos tradicionais não costumam ser eficazes para atingir o objetivo de transmitir o conhecimento de empreendedorismo, pois são demasiadamente teóricos. 
O aluno pré-empreendedor necessita de ser submetido a situações similares às que vai encontrar na prática. $O$ empreendedor aprende continuamente; se para de aprender, para de ter sucesso (Dolabela, 2008). Segundo Gibb (1999), o empreendedor aprende enquanto: soluciona problemas, executa sob pressão, interage com os pares e outras pessoas, aproveita oportunidades, copia outros empreendedores, aprende com os próprios erros e aproveita ofeedback.

DesSa maneira, o ensinar a empreender necessita de um olhar direcionado para encorajar o comportamento arrojado, criar desafios e modelos, típico de empreendedores. Há a necessidade também de se educar para lidar com situações como, frustrações, recursos limitados, processos adversos, pessoas não comprometidas onde os valores como perseverança e a determinação poderão promover a superação de limites por meio de mudanças inovadoras.

\section{Educação Financeira e Autoconhecimento}

A atitude empreendedora é um diferencial para a sustentabilidade para o mercado de trabalho, caracterizado pelo desenvolvimento do autoconhecimento, autoestima, solidariedade, contexto cultural, habilidades de comunicação, usar a tecnologia e trabalhar em equipe, a inteligência emocional, a criatividade e a habilidade para a proatividade.

Pretende-se a sensibilização sobre os fatores de influência no padrão de consumo com vistas a reduzir o desperdício e incrementar o bom uso dos recursos, incentivando a sustentabilidade nas diversas esferas da vida. O trabalho de reconhecimento do fator "ter" na vida de todos, mas não como determinante do "ser", da pessoa que se é (SELIGMAN, 2002).

As bases cognitivas, atitudinais, comportamentais e emocionais do aluno são aspectos necessários para o pleno desenvolvimento humano, para a definição profissional, bem como para a construção da empregabilidade e da atitude empreendedora. Por meio das profissões escolhidas por nossos alunos, eles irão gerar os produtos e serviços que permearão as mais variadas atividades das futuras sociedades.

Com base no Desenvolvimento e Prontidão Cognitivos, que é a capacidade de transformar ideias potencialmente significativas do sujeito, em que a aprendizagem proativa é um processo intrínseco, compreendo que cabe ao sujeito a possibilidade de reconstruir os significados de suas experiências emocionais, a partir de referenciais pessoais, tornando-o protagonista de suas escolhas. A missão do mediador, nessa perspectiva, é auxiliar o indivíduo a se tornar mais consciente e autorresponsável (AUSUBEL, 2003).

Pessoas felizes profissionalmente têm mais saúde do que aquelas que exercem profissões em que não se sentem realizadas. 0 empreendedorismo, junto aos educandos, consiste em construir uma visão de si, do mundo e do futuro que traga mais saúde e determinação pessoal diante dos projetos de vida. Isso se 
consegue, em primeiro lugar, com mais clareza nas escolhas pessoais. Os alunos precisam de um contexto seguro e acolhedor para debater seus projetos e escolhas. Além de escolher uma profissão, um dos pontos mais importantes é auxiliar o indivíduo a alcançar um bom grau de flexibilidade mental, conseguir não somente escolher a carreira, mas as atitudes que adotará em sua formação e postura de vida: na criação de seus laços sociais, nos cursos que irá escolher na formação superior e na formação extracurricular. Enfim, no conjunto de ações que vão determinar o grau de êxito futuro e satisfação em seu processo de crescimento pessoal e profissional.

O desafio educacional é lidar com as aprendizagens cognitivas, afetiva e motora, de forma a gerar significados positivos a partir dessas experiências. O desenvolvimento cognitivo ou capacidade funcional aumenta naturalmente com a idade e a experiência escolar. Esta prontidão refere-se à disponibilidade de ideias de matérias específicas, bem organizadas na estrutura cognitiva, que são essenciais para a compreensão e manipulação de novas ideias (NOVAK, 2010).

A visão integrada do funcionamento cérebro/corpo e das inter-relações entre as diversas áreas da vida de um ser humano é um ponto angular na análise do homem pela perspectiva cognitiva. A neurociência, por meio de inúmeros achados recentes, pode nos mostrar que somos um todo interligado e em constante circularidade entre os processos de pensar, sentir e agir. Como é esperado, este grau de prontidão no desenvolvimento não ocorre na ausência de estímulo intelectual, sendo ele na escola ou em casa (AUSUBEL, 2003).

Os seres humanos são múltiplos, emocionais e cognitivos, feitos de ambiguidades, desejos, sonhos, projetos, marcas e mesclas de nossa história e cultura, com receios e aspirações das mais diversas.

O conhecimento do indivíduo sobre si mesmo, base fundamental para poder elevar-se a uma condição de protagonista, livre e escolhedor autêntico do que é e do que será. A percepção e o reconhecimento de si e dos outros, no que se refere a sentimentos e atitudes, e o impacto de nossas ações nas outras pessoas são condições essenciais para o estabelecimento da empatia, ingrediente indispensável para a construção da inteligência emocional e estabelecimento de boas conexões e um convívio sadio e produtivo com as pessoas.

\section{Metodologia}

A escola, alvo deste estudo, possui em seu currículo para o ensino fundamental as disciplinas de filosofia, matemática, geografia, história, ciências, português, inglês, educação física, arte e empreendedorismo. Esta pesquisa partiu de um projeto da escola sobre a necessidade de se ensinar economia doméstica por meio da cesta básica e abarcou outras disciplinas. A escola tem uma peculiaridade de ensinar Empreendedorismo cultivando uma cultura com os alunos de maior sensibilidade para trabalhar temas que envolvam a participação ativa dos alunos e professores em pesquisa de campo. 
Os dados colhidos das análises, a ser verificado no capítulo 'Resultados', foram realizados na disciplina de Empreendedorismo, mas os cálculos em Matemática, as discussões sobre cidadania e dignidade (com a quantidade de itens de uma cesta básica para uma família) foram realizadas em Filosofia e, por fim, a ortografia das palavras foi trabalhada na disciplina de Português. Desta forma, pode-se ministrar economia doméstica de forma transdisciplinar envolvendo muitas facetas escolares e muitos professores, pois outra particularidade da escola é que para cada disciplina, desde o primeiro ano, há um professor com aptidão para ministrar aquela matéria em específico.

\section{Classificação da Pesquisa}

Esta pesquisa é de cunho aplicado, pois mostrou uma intervenção numa escola da região sul com alunos do ensino fundamental na disciplina de empreendedorismo. De acordo com Gerhardt e Silveira (2009), a pesquisa aplicada objetiva gerar conhecimentos para aplicação prática, dirigidos à solução de problemas específicos e que envolve verdades e interesses locais. A problematização do estudo foi tratada de forma predominantemente quantitativa, pois os dados obtidos foram trabalhados numericamente e graficamente. Silva (2005) corrobora, descrevendo que a pesquisa quantitativa é aquela em que se utiliza de linguagem matemática para tratamento dos dados.

Quanto aos objetivos, a pesquisa foi classificada como explicativa, pois explica, através dos resultados obtidos, o porquê tem a preocupação de identificar os fatores que determinaram os resultados obtidos com as crianças, tal como explicita (GERHARDT E SILVEIRA, 2009).

Para Silva (2005), do ponto de vista dos procedimentos técnicos, a pesquisa foi classificada como "de levantamento", que é quando a pesquisa envolve a interrogação direta das pessoas cujo comportamento se deseja conhecer. E foi enviado, para casa de cada criança, um questionário perguntando quantos e qual quantidade de itens da cesta básica cada família consumia por mês. O questionário como uma técnica de coleta de dados é difundido e conhecido. Oliveira (2003, p. 71) afirma que "o questionário constitui-se de uma série ordenada de perguntas relacionadas a um tema central, que são respondidas sem a presença do entrevistador". O questionário foi utilizado por ser a maneira mais indicada para se aplicar este estudo em questão.

\section{QUESTIONÁRIO ENVIADO PARA AS FAMÍLIAS (SURVEY)}

Primeiramente os alunos partícipes deste estudo, matriculados no 40 e $5^{\circ}$ anos de uma escola particular da região Sul, responderam qual a quantidade de comida estimada consumida por mês em seus lares, de acordo com o questionário a seguir elaborado pelas pesquisadoras. 
e-Mosaicos - Revista Multidisciplinar de Ensino, Pesquisa, Extensão e Cultura do Instituto de Aplicação Fernando Rodrigues da Silveira (CAp-UERJ)

V. 6 - N. 12 - AGOSTO 2017 - ISSN: 2316-9303

DOI 10.12957/e-mosaicos.2017.28940

Questionário

\begin{tabular}{|c|c|c|}
\hline Mantimento & Quantidade & Quantidade \\
\hline Arroz & $\mathrm{kg} / \mathrm{mês}$ & g/mês \\
\hline Farinha de Mandioca & _kg/mês & g/mês \\
\hline Açúcar Refinado & kg/mês & $\mathrm{g} / \mathrm{mês}$ \\
\hline Café em Pó & kg/mês & $\mathrm{g} / \mathrm{mês}$ \\
\hline Achocolatado em Pó & kg/mês & g/mês \\
\hline Leite em Pó & kg/mês & $\mathrm{g} / \mathrm{mês}$ \\
\hline Fubá & kg/mês & $\mathrm{g} / \mathrm{mês}$ \\
\hline Farinha de Trigo & kg/mês & g/mês \\
\hline Feijão & kg/mês & $\mathrm{g} / \mathrm{mês}$ \\
\hline Sal Refinado & kg/mês & $\mathrm{g} / \mathrm{mês}$ \\
\hline Macarrão & kg/mês & g/mês \\
\hline Óleo de Soja & LL/mês & $\mathrm{ml} / \mathrm{mês}$ \\
\hline Molho de Tomate & LL/mês & $\mathrm{ml} / \mathrm{mês}$ \\
\hline Polpa de Tomate & LL/mês & $\mathrm{ml} / \mathrm{mês}$ \\
\hline Salsicha Enlatada & latas/mês & _kg/mês \\
\hline Goiabada & pacotes/mês & kg/mês \\
\hline Pó para Refresco & pacotes/mês & \\
\hline Biscoito Salgado & pacotes/mês & \\
\hline Gelatina & pacotes/mês & \\
\hline Mistura para Bolo & pacotes/mês & \\
\hline Biscoito Recheado & pacotes/mês & \\
\hline Sardinha em Óleo & latas/mês & \\
\hline Tempero Completo & potes/mês & \\
\hline
\end{tabular}

Em seguida, o mesmo inquérito foi enviado para os pais/responsáveis das crianças com a devida explicação para elucidar o intuito da investigação.

A partir das respostas dos estudantes e dos pais/responsáveis, foi realizado o confronto dos dados para comparar como os alunos estão posicionados em relação ao que consomem em suas residências e assim, verificar a noção que possuem e 
adquiriram de sustentabilidade de acordo com o relatório da ONU dos Objetivos para - Desenvolvimento Sustentável, item 12: "Assegurar padrões de produção e de consumo sustentáveis" (ITAMARATY, 2015). Este relatório foi previamente trabalhado e amplamente explorado com as crianças nas aulas de empreendedorismo conforme as lições que receberam na escola.

Os estudantes ainda responderam o quanto eles acreditavam investir em alimentação/família de acordo com os itens elencados na cesta básica. Com estes dados, a diretora e professora de empreendedorismo comparou a expectativa deles com relação ao preço dos produtos e quantidade consumida com a realidade afirmada pelos pais/responsáveis e promoveu um debate sobre o assunto. Os temas da aula foram: - valor da cesta básica, preços dos produtos, o que os alunos incluiriam a mais na cesta básica, a importância de se comparar as marcas e verificar a etiqueta que possui a informação contendo o valor do $\mathrm{kg}$ ou do $\mathrm{L}$.

A diretora da escola foi com os alunos em um supermercado da cidade da pesquisa para colher os valores dos itens e ensiná-los a verificar o custo por quilograma ou por litro de alimento que contém nas etiquetas dos produtos, obrigatório pela Lei Federal de número 13.175 de 2015.

Entusiasmados com a participação neste estudo, uma aluna que possui um blog inclusive solicitou permissão para filmar e postar a aula de empreendedorismo que recebeu no supermercado, bem como todas as novidades que aprendeu $e$ compartilhou com os colegas.

\section{Discussão e AnÁlise dos Resultados}

Percebeu-se, pelo Gráfico 1, que a média da diferença, embora exista, não foi significativa em relação ao que os pais/responsáveis alegam consumir e o que as crianças do $4^{\circ}$ ano acreditavam ser utilizado em casa durante um mês. 
e-Mosaicos - Revista Multidisciplinar de Ensino, Pesquisa, Extensão e Cultura do Instituto de Aplicação Fernando Rodrigues da Silveira (CAp-UERJ) V. 6 - N. 12 - AGOSTO 2017 - ISSN: 2316-9303

Gráfico 1 - Consumo Real versus Consumo Estimado pelo $4^{\circ}$ ano

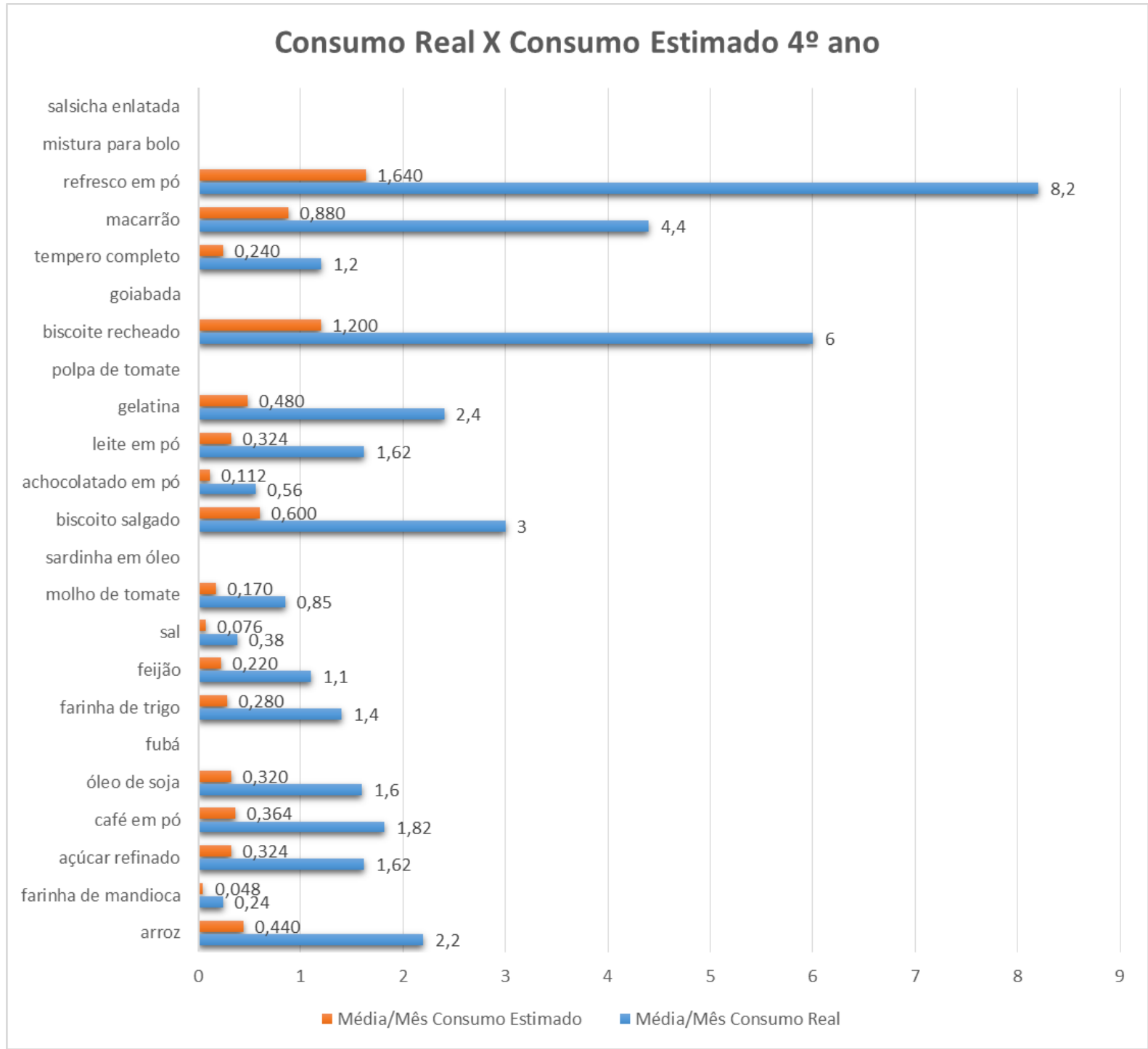

Fonte: Próprios autores

A Tabela 1 demonstra a diferença, somando-se todos os excessos ou faltas, quando comparadas com as quantidades informadas pelos pais. A Tabela 1 foi elaborada entre a do consumo real e expectativa das crianças do 40 ano, e geralmente eles acreditavam consumir menor quantidade mensalmente. 
e-Mosaicos - Revista Multidisciplinar de Ensino, Pesquisa, Extensão e Cultura do Instituto de Aplicação Fernando Rodrigues da Silveira (CAp-UERJ)

V. 6 - N. 12 - AGOSTO 2017 - ISSN: 2316-9303

DOI 10.12957/e-mosaicos.2017.28940

Tabela 1 - Diferença Total do $4^{\circ}$ ano de Consumo Real e o Esperado pelas Crianças

\begin{tabular}{|c|c|c|c|}
\hline \multicolumn{4}{|c|}{ Diferença Total do $4^{\circ}$ ano de Consumo Real e o Esperado pelas Crianças } \\
\hline Mantimentos & $\begin{array}{c}\text { Em quilogramas }(\mathrm{kg}) \text { ou } \\
\text { litros }(\mathrm{L})\end{array}$ & Fração de kg ouL & total/mês \\
\hline Arroz & 1 & 0 & 0 \\
\hline farinha de mandioca & -2 & 0,2 & $-2,8$ \\
\hline açúcar refinado & -2 & 0,1 & $-2,9$ \\
\hline café em pó & -1 & 0,1 & $-1,9$ \\
\hline óleo de soja & -2 & 0 & -1 \\
\hline fubá & 0 & 0,3 & 0 \\
\hline farinha de trigo & -2 & 0 & -6 \\
\hline feijão & -5 & 0,5 & $-4,5$ \\
\hline sal & -7 & 1,9 & $-5,1$ \\
\hline molho de tomate & 0 & $-0,001$ & 0,249 \\
\hline sardinha em óleo & -1 & latas & -1 \\
\hline biscoito salgado & -9 & pacotes & -16 \\
\hline achocolatado em pó & -5 & 0,8 & $-5,2$ \\
\hline leite em pó & 1 & 0,1 & 4,1 \\
\hline gelatina & -3 & pacotes & -5 \\
\hline polpa de tomate & -3 & 0 & -2 \\
\hline biscoito recheado & 11 & pacotes & 7 \\
\hline goiabada & 0 & pacotes & 0 \\
\hline tempero completo & -2 & pote & -5 \\
\hline macarrão & -2 & 0 & -8 \\
\hline refresco em pó & 10 & pacotes & 8 \\
\hline mistura para bolo & -1 & pacotes & -1 \\
\hline salsicha enlatada & -6 & 0 & -6 \\
\hline
\end{tabular}

Fonte: Próprios Autores

A explicação possível para esta noção de realidade, que pode ser avaliada na compilação dos inquéritos, se concretiza no fato de a maioria do alunado da escola possuir aulas de empreendedorismo desde $o 1^{\circ}$ ano do ensino fundamental.

O Gráfico 2 também versa sobre a média da diferença de opinião a respeito do consumo entre pais e alunos do $5^{\circ}$ ano. 
e-Mosaicos - Revista Multidisciplinar de Ensino, Pesquisa, Extensão e Cultura do Instituto de Aplicação Fernando Rodrigues da Silveira (CAp-UERJ) V. 6 - N. 12 - AGOSTO 2017 - ISSN: 2316-9303

Gráfico 2 - Média Consumo Real versus Consumo Estimado pelo $5^{\circ}$ ano

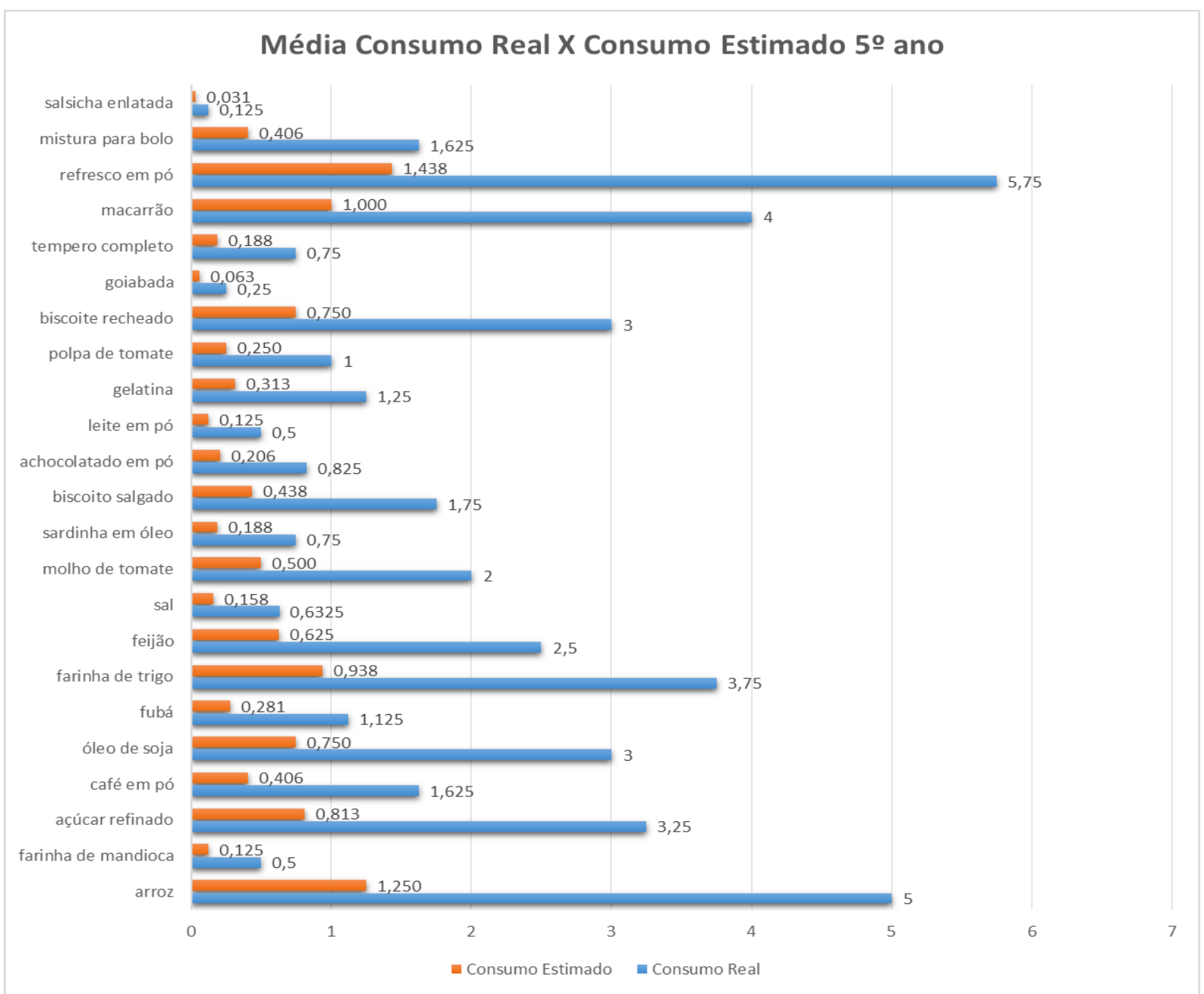

Fonte: Próprios Autores

A Tabela 2 também foi construída com intuito de demonstrar a diferença, somando-se todos os excessos ou faltas para comparar as quantidades informadas pelos pais com as quantidades informadas pelos alunos. A Tabela 2 elucida 0 consumo real e expectativa das crianças do $5^{\circ}$ ano, e, desta vez, eles pensavam que consumiam maior quantidade por mês. 
e-Mosaicos - Revista Multidisciplinar de Ensino, Pesquisa, Extensão e Cultura do Instituto de Aplicação Fernando Rodrigues da Silveira (CAp-UERJ)

V. 6 - N. 12 - AGOSTO 2017 - ISSN: 2316-9303

DOI 10.12957/e-mosaicos.2017.28940

Tabela 2 - Diferença Total do $5^{\circ}$ ano de Consumo Real e o Esperado pelas Crianças

\begin{tabular}{|c|c|c|c|}
\hline \multicolumn{4}{|c|}{ Diferença Total do $5^{\circ}$ ano de Consumo Real e o Esperado pelas Crianças } \\
\hline Mantimentos & $\begin{array}{l}\text { Em quilogramas } \\
(\mathrm{kg}) \text { ou litros }(\mathrm{L})\end{array}$ & Fração de kg ou L & total/mês \\
\hline Arroz & -1 & $-0,5$ & $-5,5$ \\
\hline farinha de mandioca & 1 & $-0,5$ & 0,5 \\
\hline açúcar refinado & 6 & $-0,5$ & 5,5 \\
\hline café em pó & -8 & 0,5 & $-7,5$ \\
\hline óleo de soja & -4 & 0 & -4 \\
\hline Fubá & 1 & 0,5 & 1,5 \\
\hline farinha de trigo & 4 & 0 & 4 \\
\hline Feijão & -8 & 0 & -8 \\
\hline Sal & -1 & $-0,07$ & $-1,07$ \\
\hline molho de tomate & 1 & $-0,5$ & 0,5 \\
\hline sardinha em óleo & 3 & latas & 3 \\
\hline biscoito salgado & 1 & pacotes & 1 \\
\hline achocolatado em pó & 1 & 0,8 & 1,8 \\
\hline leite em pó & 1 & 0 & 1 \\
\hline Gelatina & 0 & pacotes & 0 \\
\hline polpa de tomate & 0 & $-0,5$ & $-0,5$ \\
\hline biscoito recheado & 7 & pacotes & 7 \\
\hline goiabada & 0 & pacotes & 0 \\
\hline tempero completo & 0 & pote & 0 \\
\hline macarrão & 0 & 0 & 0 \\
\hline refresco em pó & 21 & pacotes & 21 \\
\hline mistura para bolo & 1,5 & pacotes & 1,5 \\
\hline salsicha enlatada & 0 & 0 & 0,5 \\
\hline
\end{tabular}

Fonte - Próprios autores (2017)

A Tabela 2, como foi elaborada com os dados das crianças mais velhas (em torno de 10 anos), quando comparadas com a Tabela 1 (crianças em torno de 9 anos), mostra uma discreta diferença entre os pais e os alunos, sendo que os estudantes do $5^{\circ}$ ano têm uma noção maior do consumo que realmente acontece em seus lares. 
Os Gráficos3 e 4 mostram a diferença em relação à pergunta realizada aos alunos: "Quanto você acredita que sua família investe em alimentação com os itens da cesta básica?". E o valor que eles estimaram foi bem diferente daquele que eles colheram na pesquisa de campo que realizaram no supermercado.

\section{Gráfico 3 - Média Financeira do $4^{\circ}$ ano}

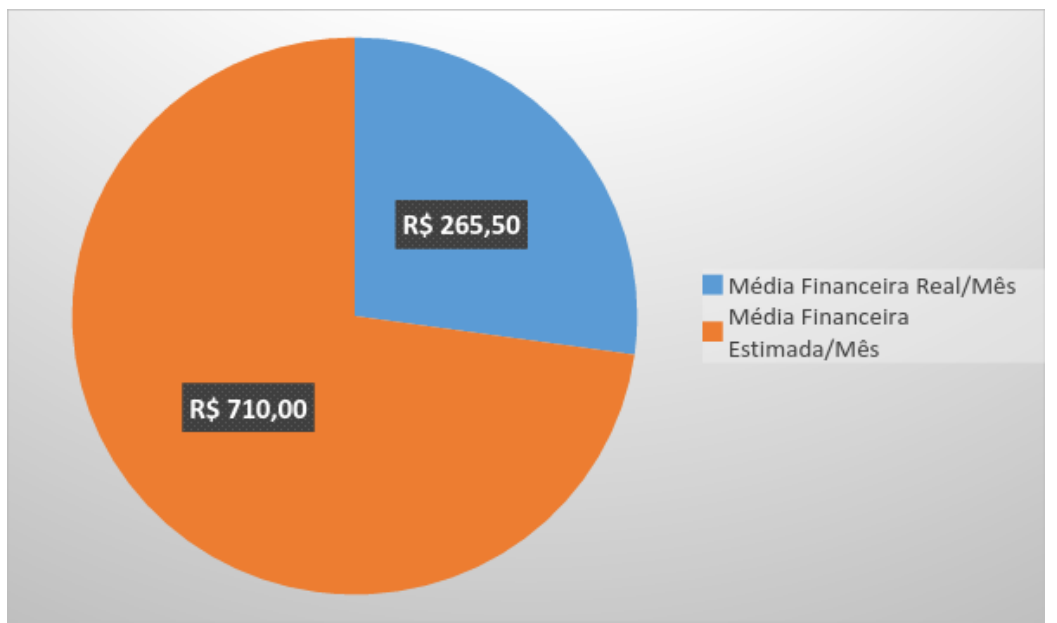

Fonte: Próprios autores

Gráfico 4 - Média Financeira do $5^{\circ}$ ano

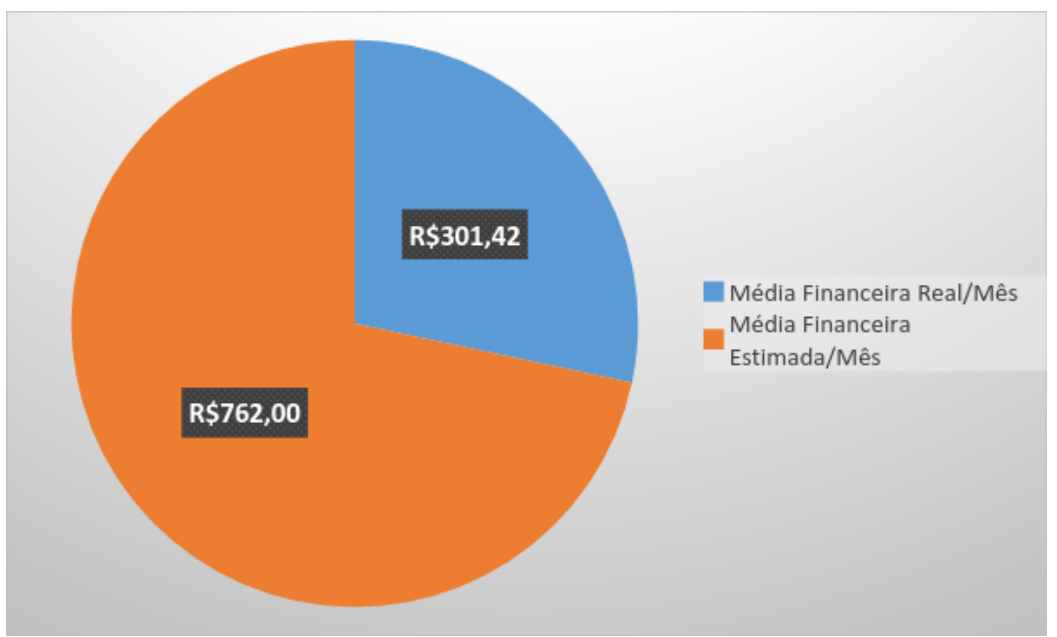

Fonte: Próprios autores

A diferença em Reais (moeda monetária), de um ano escolar para outro, foi pequena tanto para o gasto real com alimentação quanto para o que eles estimaram gastar. Porém, foi grande ao se avaliar a realidade em comparação com a expectativa dos alunos, reafirmando a necessidade de se ter continuamente educação para o trabalho por meio de aulas que abordem economia e temas relevantes da sociedade. Assim, estudar empreendedorismo desde o Ensino 
Fundamental justifica-se para auxiliar as crianças a visualizar e projetar um equilíbrio financeiro para a vida adulta com atitudes economicamente saudáveis.

Com estas aulas, eles adquiriram a real noção entre os alimentos por quilograma ou litro, puderam saber o preço de uma cesta básica e o quanto consomem dela mensalmente, bem como a distância que estão da realidade que os pais disseram consumir. Assim, desde tenra idade já são ensinados a realizar economia doméstica para uma sociedade economicamente mais equilibrada e sustentável.

\section{CONSIDERAÇÕES FinaIS}

Dos alunos matriculados na Escola particular da região Sul, 77,78\% possuem aula de empreendedorismo no currículo desde $01^{0}$ ano do ensino fundamental, alicerçando este bom desempenho acerca da quantidade de produtos consumidos mensalmente em cada residência.

Quanto aos gastos com a alimentação, os estudantes ainda demonstraram a necessidade de se investir no ensino de valores socioeconômicos, resgatando importantes noções financeiras. Assim, a escola auxilia a inserir o aluno no contexto de cidadania necessário para leitura e interpretação de dados relativos a saber poupar, gastar e pagar, de acordo com suas posses desde a infância.

Ainda que a escola não possua uma disciplina específica de empreendedorismo, o tema pode ser trabalhado de forma transdisciplinar por disciplinas como Matemática, Filosofia e Português, por exemplo, trazendo conteúdos do cotidiano para as crianças se familiarizarem com as questões globais e, assim, aprenderem a gerir, administrar as questões locais.

Quando se ensina empreendedorismo, mobiliza-se o aluno quanto à capacidade de identificação de sentimentos, reflexão sobre eles e projeção sobre o que se pode e o que se quer fazer. Dessa forma, dá-se a compreensão de cada indivíduo como ser histórico (que tem sua história passada, vive no presente e consegue planejar, imaginar o futuro) e o consequente aprimoramento do exercício de escolhas conscientes e solidárias, pois, quando não se aprende a escolher, tornase vítima do automatismo, das contingências e de fatores externos.

\section{REFERÊNCIAS BIBLIOGRÁFICAS}

AUSUBEL, David P. Aquisição e retenção de conhecimentos: uma perspectiva cognitiva. Lisboa: Plátano, v. 1, 2003.

BAUMAN, Zygmunt. Identidade. Tradução de Carlos Alberto Medeiros. Rio de Janeiro: Jorge Zahar, 2005. 
DOI 10.12957/e-mosaicos.2017.28940

BRASIL. Lei no 13.175, de 21 de outubro de 2015. Disponível em: https://www.planalto.gov.br/ccivil 03/ ato2015-2018/2015/lei/l13175.htm. Acesso em 19 Jan. 2017.

CHRISTAKIS, Nicholas. O poder das conexões. Rio de Janeiro: Campus, 2009.

FLORES, Danusa Cunha; HOELGEBAUM, Marianne; SILVEIRA, Amélia. O Ensino de Empreendedorismo nos Cursos de Pós Graduação em Administração no Brasil. In: Revista de Negócios. Blumenau, v.13, n.2, p.93-104, Abr/Jun 2008.

FREIRE, Paulo. Pedagogia do Oprimido. São Paulo: Paz e Terra, 1974.

GERHARDT, Tatiana Engel; SILVEIRA, Denise Tolfo. Métodos de pesquisa. PLAGEDER, 2009.

GIANNETTI, E. Felicidade. São Paulo: Companhia das Letras, 2002.

GIBB, Allan. Can we Build Effective entrepreneurship Through Management development? In: Journal of General Management, v. 24, n. 4, p. 1-21, 1999.

GHIRALDELLI JR, Paulo. Didática e teorias educacionais. Rio de janeiro: DP\&A, 2000.

HONIG, Benson. Entrepreneurship education: Toward a model of contingency-based business planning. In: Academy of Management Learning \&Education, v. 3, n. 3, p. 258-273, 2004.

Ministérios das Relações Exteriores do Brasil (ITAMARATY). Objetivos para 0 Desenvolvimento Sustentável. (2015). Disponível em: http://www.itamaraty.gov.br/ images/ed_desenvsust/ODSportugues12fev2016.pdf. Acesso em 16 de agosto de 2016.

NOVAK, Joseph D.; CAÑAS, Alberto J. A teoria subjacente aos mapas conceituais e como elaborá-los e usá-los. In: Práxis Educativa, v. 5, n. 1, p. 9-29, 2010.

OLIVEIRA, Antonio Benedito Silva. Métodos e técnicas de pesquisa em contabilidade. São Paulo: Saraiva, 2003.

SELIGMAN, M. Felicidade Autêntica. Rio de Janeiro: Objetiva, 2002

SNYDERS, Georges; CARVALHO, Manuel Pereira de. Pedagogia progressista. Coimbra: Almedina, 1976.

SILVA, Edna Lúcia da, MENEZES, Estera Muszkat. Metodologia da pesquisa e elaboração de dissertação. Florianópolis: UFSC, 2005. 
VIEIRA, Saulo Fabiano Amâncio; MELATTI, Gerson Antonio; RIBEIRO, Paula Regina. O Ensino de Empreendedorismo nos Cursos de Graduação em Administração: Um Estudo Comparativo entre as Universidades Estaduais de Londrina e Maringá. In: Revista Admin. Santa Maria: UFSM, v. 4, n.1, p.288-301, mai/ago 2011. 